\title{
The Effects of Market Structure on Industry Growth: Rivalrous Nonexcludable Capital
}

\author{
Christos Koulovatianos* \\ University of Vienna \\ e-mail: koulovc6@univie.ac.at
}

\author{
Leonard J. Mirman \\ University of Virginia \\ e-mail: $\operatorname{lm} 8 \mathrm{~h} @$ virginia.edu
}

September 9, 2005

* Corresponding author, Department of Economics, University of Vienna, Hohenstaufengasse 9, A-1010, Vienna, Austria. E-mail: koulovc6@univie.ac.at, Tel: +43-1-427737426, Fax: +431-42779374. We thank Gerhard Sorger, an anonymous associate editor of this journal, and an anonymous referee for their useful suggestions, and also participants at the SED 2004 meetings in Florence and seminar participants at the University of Vienna and Sabancı University for their comments. Koulovatianos thanks the Leventis foundation and the Austrian Science Fund under project P17886, for financial support. 


\title{
The Effects of Market Structure on Industry Growth: Rivalrous Nonexcludable Capital
}

\begin{abstract}
We analyze imperfect competition in dynamic environments where firms use rivalrous but nonexcludable industry-specific capital that is provided exogenously. Capital depreciation depends on utilization, so firms influence the evolution of the capital equipment through more or less intensive supply in the final-goods market. Strategic incentives stem from, (i) a dynamic externality, arising due to the non-excludability of the capital stock, leading firms to compete for its use (rivalry), and, (ii) a market externality, leading to the classic Cournot-type supply competition. Comparing alternative market structures, we isolate the effect of these externalities on strategies and industry growth.
\end{abstract}

Keywords: Cournot competition, oligopolistic non-cooperative dynamic games, tragedy of the commons

JEL classification: D43, D92, L13, Q20, O12

\author{
Christos Koulovatianos \\ Leonard J. Mirman \\ Department of Economics \\ Department of Economics \\ University of Vienna \\ University of Virginia \\ Hohenstaufengasse 9 \\ 114 Rous Hall \\ A-1010, Vienna, Austria. \\ Charlottesville, VA 22903, USA. \\ e-mail: koulovc6@univie.ac.at \\ e-mail: lm8h@virginia.edu
}




\section{Introduction}

The role of capital deepening on economic growth is usually studied through highly aggregated growth models. In these models, typically focusing on the macroeconomy, perfect competition is the prevailing market structure. Yet, little attention has been paid to the forces and incentives behind capital deepening and growth in smaller markets, like industries.

In a significant number of industries, firms sell their final products in imperfectly competitive markets. Classic Cournot-type oligopolistic incentives arise in such industries. Yet, whenever specific capital is useful for production, each firm's intertemporal capital allocation is an additional strategic lever, apart from its supply strategy. By accumulating capital, a firm can use its productive capacity to affect its oligopolistic competitiveness and profit margin over time.

We focus on industries with production that relies on the use of a specific type of capital, infrastructure, specific equipment, or a natural resource, which is provided exogenously. Capital in our analysis is nonexcludable, it can be used at no cost by all firms, and also rivalrous, subject to a first-come first-served rule or to congestion costs. Moreover, capital in our study depreciates with utilization. Thus, higher aggregate production in the industry today implies lower capital in the future.

The key to understanding the link between market structure and industry dynamics in such an environment is to analyze the fundamental strategic incentives that arise, (i) from the interaction of firms in the market for the final good, a market externality among firms, and (ii) from the interaction of firms in the process that determines future capital deepening, a dynamic externality among firms. ${ }^{1}$ To isolate the impact of each externality on aggregate industry production, and hence, industry growth, we build a parametric model that allows

1 The terms "dynamic externality" and "market externality" were coined by Mirman [9], who pointed out the distinction of the two effects in the necessary conditions of a general framework of fishing games. 
us to encompass four market structures, namely, (a) a single firm monopolistic industry, (b) an industry with two monopolists selling the final product in their own separate markets but utilizing capital from the same provider, (c) a duopoly with firms selling in the same market and utilizing capital from the same provider, and (d) a duopoly with firms utilizing capital from separate providers.

The nature of the two externalities brings significant technical complexities into the dynamic problem faced by each firm in such noncooperative games. The presence of these externalities in the dynamic game makes the strategies of competitors part of the structural maximization problem of a firm. In order that the problem of each firm be well-defined, the primitives of the model should imply that the equilibrium strategies possess convenient functional properties. So, we model the economic environment to obtain linear equilibrium strategies that make the analysis tractable. In order to accomplish this we use homogeneous or isoelastic functions to capture consumer demand and the primitives of firms. Our parametric model is essentially an extension of the example of Levhari and Mirman [8], that is designed to accommodate the market externality, as well as the dynamic externality.

In a fashion similar to Levhari and Mirman [8], a comparison of market structure (a) with (b) reveals the impact of the dynamic externality. Our results suggest the dominance of a commons problem, i.e. more firms induce higher aggregate supply and lower growth. ${ }^{2}$ The comparison of (a) with (c), and of (b) with (c), reveal the impact of the market externality in addition to the dynamic externality, the core contribution of this paper. ${ }^{3}$ Compared to the benchmark monopoly, we find that the aggregate supply of firms in each period is always

2 See, for example, Mirman [9], Levhari and Mirman [8], who were the first to analyze the commons problem using noncooperative dynamic games, and also Amir [1], Sundaram [11], Benhabib and Radner [2], Dutta and Sundaram [3] and [4], and Sorger [10], who apply their analysis to natural-resource games, focusing mostly on the commons problem.

3 To our knowledge, the economic impact of the market externality on final good supply strategies in such a dynamic environment has not been studied before. 
higher. But compared to the market structure of two monopolists with common capital utilization, the impact depends on the model's primitives. We find that below a threshold level for the demand elasticity (depending only on the number of firms in the market), the aggregate supply of firms increases compared to the structure of two monopolists. When the demand elasticity is higher than that threshold level, the aggregate supply of two monopolists can be higher than the aggregate supply of the duopolists, depending on other primitives. These primitives are: convexity of the cost function, elasticity of capital renewal, interest rates, and a utilization-dependent depreciation technology.

With respect to market structure (d), a duopoly with two capital providers, we show that this problem is very complex, as it involves two capital stocks and strategic considerations about the evolution of both stocks by both firms. Yet, we characterize, analytically, the symmetric strategies of firms within our parametric framework, which turn out to be linear with respect to the two capital stocks.

Our framework and analysis fit directly industries with production based on natural resources. However, they are not limited to these applications. Indeed they are applicable in industries that utilize capital from outside providers and the capital is rivalrous and nonexcludable. Examples of publicly provided infrastructure are airports, harbors, roads, pipelines, transmission grids, railroads, or telecommunications lines. Governments determine and control the full provision and the growth rate of the available public infrastructure. Typically, governments follow rules for financing its maintenance or growth. ${ }^{4}$ Capital in our study depreciates with utilization. So, the evolution of specific capital, and, consequently the long-run growth of industries that use it, depend on the production, i.e., aggregate supply decisions of firms; more intensive use increases the cost of its maintenance or speeds up

4 For example, a government may use a constant fraction of the fiscal budget every year in order to finance a certain type of infrastructure. 
depreciation. Often, governments impose special taxes on firms for the use of roads or ports, in order to slow down the depreciation of these structures. ${ }^{5}$

Another important example of specific capital is human resources in basic research. Basic research activities, usually taking place in universities, target inventions. Research for marketable innovations, on the other hand, is usually financed by firms. Industries may take human resources out of universities, out of basic research activities, in order to direct them to market-oriented innovations. ${ }^{6}$ The time of researchers is rivalrous and also wasted from producing inventions, a critical determinant for the growth rate of revolutionary new knowledge.

In section 2 we present the general formulation of the firm problems in market structures with rivalrous and nonexcludable capital, whereas in Section 3 we conduct our economic analysis through a parametric model. In Section 4 we analyze the case of a duopoly where firms utilize capital from their own, exclusive provider.

\section{Economic environment and alternative market structures}

Time is discrete with an infinite horizon, $t=0,1, \ldots$ Consumer demand for the final good, $q$, is characterized by the inverse-demand function, $p_{t}=D\left(q_{t}\right)$, in each period. Specific capital, denoted as $k$, is necessary for production. In particular, the production of $q$ units of the

5 An extension is to endogenize the supply process of public infrastructure. Using modeling and theoretical insights from our current paper can help towards this direction. For example, utilizing the techniques of the present study, Koulovatianos and Mirman [6] examine the link between market structure and industry growth when firms pursue cost-reducing knowledge accumulation through R\&D investment, using an alternative model specification that endogenizes the private provision of capital (knowledge in that case). Yet, they point out the same strategic elements behind firm behavior, namely the importance of the dynamic and the market externality.

6 For example, the high attrition rates in computer science graduate programs or engineering, can be explained by the effort of companies to tempt students to work on innovations concerning their IT products, by offering higher salaries. 
final good requires that $\psi(q)$ units of capital are consumed by utilization, with $\psi^{\prime}(q)>0 .^{7}$ Capital obeys an exogenous rule of renewal, depending on previous period's stock, namely, $k_{t+1}=f\left(k_{t}\right)$, with $f^{\prime}(k)>0$. When $N$ firms exploit the same capital stock in order for each of them to produce a quantity, $q_{i, t}$ in period $t$, with $i \in\{1, \ldots, N\}$, the law of motion of capital is,

$$
k_{t+1}=f\left(k_{t}\right)-\sum_{i=1}^{N} \psi\left(q_{i, t}\right) .
$$

In order to produce output, firms also need to hire labor. The cost of labor, $l$, in period $t$, is given by, $c_{t}=c\left(l_{t}\right)$, where $c^{\prime}>0$. The capital stock has a positive effect on production capacity. The capital stock augments the productivity of labor, reducing per unit production costs. In the case of infrastructure, more infrastructure means less congestion during productive activities. When capital is a natural resource, abundance of the resource reduces search costs or costs of extraction of a unit of the resource. The production technology is given by $q_{t}=F\left(k_{t}, l_{t}\right)$, with $F_{2}>0$ and $F_{1}, F_{12} \geq 0$. Hence, for a particular level of available capital, $k$, in order to produce a certain quantity of final good, $q$, at least $l_{t}=L\left(k_{t}, q_{t}\right)$ units of labor are needed (where $L_{1} \leq 0$, and $L_{2}>0$ ). Substituting the least necessary labor for producing $q$ into $c\left(l_{t}\right)$, the cost for producing the final good, given a specific level of capital is, $c_{t}=c\left(L\left(k_{t}, q_{t}\right)\right) \equiv C\left(k_{t}, q_{t}\right)$, with $C_{2}>0$ and $C_{1} \leq 0$.

\subsection{The Dynamic Monopoly}

The objective of the dynamic monopoly, our benchmark market structure, is to determine a supply-quantity decision rule as a function of the available capital, $q=Q(k)$, so that

7 So, in the case where capital is some form of infrastructure, capital depreciates endogenously. Capital utilization wears equipment out, or it leaves less time for its maintenance. This idea of capital utilization is also studied by Greenwood et. al. [5] in a general-equilibrium framework. In the case where capital is a natural resource (renewable or not) and units of this natural resource are necessary as raw material for producing the final good, producing a certain level of output requires the consumption of part of this stock. 
lifetime profits,

$$
\sum_{t=0}^{\infty} \delta^{t}\left[D\left(q_{t}\right) q_{t}-C\left(k_{t}, q_{t}\right)\right],
$$

are maximized, given $k_{0}>0$. Here, $\delta \equiv 1 /(1+r)$, the profit discount factor, is determined by an exogenous constant interest rate $r>0$.

The problem of the monopolist can be written in Bellman-equation form,

$$
V_{M}(k)=\max _{q \geq 0}\left\{D(q) q-C(k, q)+\delta V_{M}(f(k)-\psi(q))\right\}
$$

which yields the Euler equation,

$$
\frac{D(q)+D^{\prime}(q) q-C_{2}(k, q)}{\psi^{\prime}(q)}=\delta\left\{-C_{1}(\widehat{k}, \widehat{q})+\frac{D(\widehat{q})+D^{\prime}(\widehat{q}) \widehat{q}-C_{2}(\widehat{k}, \widehat{q})}{\psi^{\prime}(\widehat{q})} f^{\prime}(\widehat{k})\right\},
$$

where $\widehat{q}$ is the output strategy of the firm in the subsequent period. A static monopoly sets the right-hand side of equation (4) to zero, while a dynamic monopoly takes into account the influence that its current supply has on the evolution of capital in the future. The Euler equation (4) serves as the benchmark equation for understanding the strategic elements that appear in other market structures, when the dynamic and the market externality are introduced.

\subsection{Two monopolists utilizing capital from the same provider: the dynamic externality}

Consider two identical firms, $A$ and $B$, each selling in their own market as a monopolist, facing the same demand function, having the same cost function, and utilizing capital from the same provider. So, capital evolves according to, $k_{t+1}=f\left(k_{t}\right)-\psi\left(q_{A, t}\right)-\psi\left(q_{B, t}\right)$, i.e., the two monopolists have a direct capital accumulation interaction. The presence of both firms using the same source of capital gives rise to a dynamic externality. 
The problem of firm $A$ in Bellman equation form is given by,

$$
V_{A, m}(k)=\max _{q_{A} \geq 0}\left\{D\left(q_{A}\right) q_{A}-C\left(k, q_{A}\right) q_{A}+\delta V_{A, m}\left(f(k)-\psi\left(q_{A}\right)-\psi\left(Q_{B, m}(k)\right)\right)\right\}
$$

where $V_{A, m}$ is the value function of firm $A$ and $Q_{B, m}(k)$ is the supply strategy, as a function of the capital stock, of firm $B .^{8}$ The problem of firm $B$ is given by a Bellman equation similar to (5), with the roles of $A$ and $B$ switched. With $Q_{B, m}(k)$, the strategy of firm $B$, being part of the Bellman equation of firm $A$, it is not generally possible to identify conditions that imply the concavity of $V_{A, m}$, the existence of equilibrium, or useful properties of strategies, such as continuity and monotonicity. ${ }^{9}$

The necessary condition implied by (5) is,

$$
\begin{aligned}
& \frac{D\left(q_{A}\right)+D^{\prime}\left(q_{A}\right) q_{A}-C_{2}\left(k, q_{A}\right)}{\psi^{\prime}\left(q_{A}\right)}=\delta\left\{-C_{1}\left(\widehat{k}, \widehat{q}_{A}\right)+\right. \\
& \left.+\frac{D\left(\widehat{q}_{A}\right)+D^{\prime}\left(\widehat{q}_{A}\right) \widehat{q}_{A}-C_{2}\left(\widehat{k}, \widehat{q}_{A}\right)}{\psi^{\prime}\left(\widehat{q}_{A}\right)}\left[f^{\prime}(\widehat{k})-\psi^{\prime}\left(Q_{B}(\widehat{k})\right) Q_{B}^{\prime}(\widehat{k})\right]\right\},
\end{aligned}
$$

where $\widehat{q}_{A}$ is the output strategy of firm $A$ in the next period. The difference between the necessary condition of the benchmark monopoly, (4), and (6), is that the term $f^{\prime}(\widehat{k})$ is replaced by $f^{\prime}(\widehat{k})-\psi^{\prime}\left(Q_{B}(\widehat{k})\right) Q_{B}^{\prime}(\widehat{k})$. The dynamic externality is due to the presence of the other player's strategy in the production of future capital.

8 We denote the setup of two monopolists exploiting capital from the same provider using the subscript ' $m$,' distinguishing it from the benchmark monopoly model of the previous subsection, which goes with the subscript ' $M$.'

9 Mirman [9] presents examples of 'classic' or seemingly 'innocent' (at least in the single monopolist case) functional forms used to capture the fundamentals of this two-monopolist setup, where the value function $V_{A, m}$ is not concave, or not continuous, and the strategy $Q_{A, m}$ is not continuous or monotonic. In fact, in many cases $Q_{A, m}$ is not a function, but a correspondence. Yet, Levhari and Mirman [8] use specific parametric forms in order to overcome the technical complexities arising from the difficulty in characterizing $Q_{B, m}(k)$. In particular, their functional forms imply that $Q_{B, m}(k)$ is a linear function in $k$. In our parametric framework that appears in the following section, $Q_{B, m}(k)$ is also linear in $k$, and thus $V_{A, m}$ is concave throughout the whole domain of $k$. So, we proceed under the convention that every desirable property is present. 


\subsection{Duopoly with firms utilizing capital from the same provider:adding the market externality}

When the second firm is also present in the same market for the final good, the Bellman equation of firm $A$ becomes,

$$
V_{A, d}(k)=\max _{q_{A} \geq 0}\left\{D\left(q_{A}+Q_{B}(k)\right) q_{A}-C\left(k, q_{A}\right)+\delta V_{A, d}\left(f(k)-\psi\left(q_{A}\right)-\psi\left(Q_{B}(k)\right)\right)\right\},
$$

where $Q_{B}(k)$ is the supply strategy of firm $B$, and $V_{A, d}(k)$ is the value function of $A$, denoting this market structure using the subscript " $d$." The corresponding necessary condition is now,

$$
\begin{array}{r}
\frac{D\left(q_{A}+Q_{B}(k)\right)+D^{\prime}\left(q_{A}+Q_{B}(k)\right) q_{A}-C_{2}\left(k, q_{A}\right)}{\psi^{\prime}\left(q_{A}\right)}=\delta\left\{D^{\prime}\left(\widehat{q}_{A}+Q_{B}(k)\right) \widehat{q}_{A} Q_{B}^{\prime}(\widehat{k})-\right. \\
-C_{1}\left(\widehat{k}, \widehat{q}_{A}\right)+\frac{D\left(\widehat{q}_{A}+Q_{B}(\widehat{k})\right)+D^{\prime}\left(\widehat{q}_{A}+Q_{B}(\widehat{k})\right) \widehat{q}_{A}-C_{2}\left(\widehat{k}, \widehat{q}_{A}\right)}{\psi^{\prime}\left(\widehat{q}_{A}\right)} \times \\
\left.\times\left[f^{\prime}(\widehat{k})-\psi^{\prime}\left(Q_{B}(\widehat{k})\right) Q_{B}^{\prime}(\widehat{k})\right]\right\} .
\end{array}
$$

As in the previous section, the dynamic externality is embodied in the term $\psi^{\prime}\left(Q_{B}(\widehat{k})\right) Q_{B}^{\prime}(\widehat{k})$, appearing at the end of the right hand side of equation (8). Yet, the terms $Q_{B}(k)$ and $Q_{B}(\widehat{k})$ also appear on the current and next period's marginal profit of firm A. More interestingly, as the term $D^{\prime}\left(\widehat{q}_{A}+Q_{B}(k)\right) \widehat{q}_{A} Q_{B}^{\prime}(\widehat{k})$ of (8) reveals, firm $A$ takes into account the impact of the change in next period's supply strategy of the competitor, $Q_{B}(\widehat{k})$, on next period's marginal revenue of $A$, through the competitor's manipulation of future supply. This is a pure Cournot consideration due to a market competitor, i.e., a market externality.

\section{A parametric model encompassing all three market structures}

We have shown that there are two externalities present when two firms supply in the same market and utilize capital from the same provider, a dynamic externality and a market 
externality. From these externalities, strategic incentives arise due to the interaction of the firms with each other in the market for the final good, as well as in the process that determines future capital deepening. These incentives are fundamental to the link between market structure and industry dynamics. However, we are not able to characterize the economic impact of these externalities on growth, since the model we have described so far is too general to study in this setting. To achieve this goal, we develop a common parametric framework that encompasses all three market structures that were analyzed in the previous section.

Let the inverse demand function in the market for the final product, $q$, be,

$$
D(q)=q^{-\frac{1}{\eta}}, \quad \text { with } \eta>1
$$

and

$$
f(k)=\left(\alpha k^{1-\frac{1}{\eta}}+\phi\right)^{\frac{\eta}{\eta-1}} \quad \text { with } \phi \geq 0
$$

i.e. the intertemporal production function of capital is a CES function. Endogenous depreciation is captured by the function,

$$
\psi(q)=\theta q, \quad \text { with } \theta \in(0,1]
$$

In other words, the depreciation of capital is proportional to the supply of the final good in each period. The final-good production function is,

$$
q=F(k, l)=\left(\alpha k^{1-\frac{1}{\eta}}+\phi\right)^{\frac{\zeta \eta}{\eta-1}} l^{v}, \quad \text { with } \zeta \in(0,1) \text { and } v>0 .
$$

The labor-cost function is, $c(l)=\nu l^{\xi}$, with $\nu \in(0,1)$ and $\xi>0$. Therefore, after solving (11) for $l$, which yields $L(k, q)$, the cost function is,

$$
C(k, q)=c(L(k, q))=\nu\left(\alpha k^{1-\frac{1}{\eta}}+\phi\right)^{-\frac{\xi \zeta \eta}{v(\eta-1)}} q^{\frac{\xi}{v}}=\nu[f(k)]^{-\beta} q^{\rho},
$$

where $\beta \equiv \xi \zeta / v$ and $\rho \equiv \xi / v$. 


\subsection{Parameter restrictions and scope of analysis}

In order to obtain strategies of the form $Q(k)=\omega f(k)$ for all firms and for all market structures, we set the restrictions,

$$
\rho-\beta=1-\frac{1}{\eta}
$$

and

$$
\rho>1-\frac{1}{2 \eta}
$$

The first parameter restriction, given by (13), implies linear strategies, while the second constraint, (14), guarantees a unique equilibrium in all market structures.

The parameters, $\alpha, \phi, \eta, \theta, v, \xi, \phi$, give enough degrees of freedom for studying the empirical link between the market structure and the growth rate in industries. Moreover, as we prove below, none of the strategies is influenced by the value of parameter $\phi$. Yet, different values for parameter $\phi$ imply different dynamics and the selection of $\phi$ is useful for addressing different economic questions. Specifically, (i) by setting $\phi=0$ and $\alpha \in\left[1, \frac{1}{\delta}\right]$, the intertemporal production function of capital is $f(k)=\alpha^{\frac{\eta}{\eta-1}} k=Z k$, a growth theory ingredient that can lead to perpetual growth for the market if $\alpha \in\left(1, \frac{1}{\delta}\right],{ }^{10}$ and, (ii) by setting $\phi>0$ and $\alpha \in(0,1)$, the model implies a zero growth steady state.

\subsection{Equilibrium in the three market structures}

For the cases of, (i) the benchmark monopolist (carrying the subscript " $M$ "), (ii) two monopolists utilizing capital from the same provider (subscript " $m$ "), and (iii) duopolists utilizing capital from the same provider (subscript "d"), the state space of all these three games is one-dimensional, namely there is one state variable, $k$. Thus, we can accommodate the calculation of the strategies in all three market structures in a single presentation.

10The upper bound $\frac{1}{\delta}$ on the parameter $\alpha$ guarantees the boundedness of the value function of each firm. 
Let $N_{\mu}$ be the number of firms in the same market, with $N_{\mu} \in\{1,2\}$, and also let $N_{\kappa}$ be the number of firms utilizing capital from the same source, with $N_{\kappa} \in\{1,2\} .{ }^{11}$ The maximization problem of firm $j \in\left\{1, \ldots, N_{\mu}\right\} \cap\left\{1, \ldots, N_{\kappa}\right\}$ is given by,

$$
\max _{\left\{\left(q_{j, t}, k_{t+1}\right)\right\}_{t=0}^{\infty}} \sum_{t=0}^{\infty} \delta^{t}\left[\left(\sum_{i=1}^{N_{\mu}} q_{i, t}\right)^{-\frac{1}{\eta}} q_{j, t}-\nu y_{t}^{-\beta} q_{j, t}^{\rho}\right]
$$

subject to,

$$
k_{t+1}=y_{t}-\theta \sum_{i=1}^{N_{\kappa}} q_{i, t}
$$

given $k_{0}>0$, where $y_{t} \equiv f\left(k_{t}\right)$, with $f\left(k_{t}\right)$ given by (10), and with parameters $\beta$ and $\rho$ obeying the restrictions given by (13) and (14).

To solve problem (P1), we use the linear symmetric strategies, $q_{i, t}=\omega y_{t}$, for all other players, $i \neq j$, with $\omega$ treated as an undetermined coefficient, and we calculate the value function, obtaining,

$$
V\left(k_{0}\right)=\frac{\alpha\left(N_{\mu}^{-\frac{1}{\eta}} \omega^{1-\frac{1}{\eta}}-\nu \omega^{\rho}\right)}{1-\alpha \delta\left(1-\theta N_{\kappa} \omega\right)^{1-\frac{1}{\eta}}} k_{0}^{1-\frac{1}{\eta}}+b,
$$

where $b$ is a constant. The Bellman equation of firm $j \in\left\{1, \ldots, N_{\mu}\right\} \cap\left\{1, \ldots, N_{\kappa}\right\}$ is given by, $V(k)=\max _{q_{j} \geq 0}\left\{\left(\sum_{i=1}^{N_{\mu}} q_{i}\right)^{-\frac{1}{\eta}} q_{j}-\nu y^{-\beta} q_{j}^{\rho}+\frac{\alpha \delta\left(N_{\mu}^{-\frac{1}{\eta}} \omega^{1-\frac{1}{\eta}}-\nu \omega^{\rho}\right)}{1-\alpha \delta\left(1-\theta N_{\kappa} \omega\right)^{1-\frac{1}{\eta}}}\left(y-\theta \sum_{i=1}^{N_{\kappa}} q_{i}\right)^{1-\frac{1}{\eta}}+\delta b\right\}$, with first-order condition,

$$
\begin{aligned}
& \left(\sum_{i=1}^{N_{\mu}} \frac{q_{i}}{y}\right)^{-\frac{1}{\eta}}\left(1-\frac{\frac{q_{j}}{y}}{\eta \sum_{i=1}^{N_{\mu}} \frac{q_{i}}{y}}\right)-\rho \nu y^{\rho-\beta-1+\frac{1}{\eta}}\left(\frac{q_{j}}{y}\right)^{\rho-1}= \\
& =\frac{\alpha \delta \theta\left(1-\frac{1}{\eta}\right)\left(N_{\mu}^{-\frac{1}{\eta}} \omega^{1-\frac{1}{\eta}}-\nu \omega^{\rho}\right)}{1-\alpha \delta\left(1-\theta N_{\kappa} \omega\right)^{1-\frac{1}{\eta}}}\left(1-\theta \sum_{i=1}^{N_{\kappa}} \frac{q_{i}}{y}\right)^{-\frac{1}{\eta}} .
\end{aligned}
$$

$\overline{11 \text { For the benchmark monopoly, } N_{\mu}=N_{\kappa}}=1$. For the two monopolists with a common capital provider, $N_{\mu}=1$ and $N_{\kappa}=2$. Whereas, for the duopolists with a common capital provider, $N_{\mu}=N_{\kappa}=2$. 
Thus, applying condition (13) to (17) confirms that all strategies are of the form $q_{i, t}=\omega y_{t}$, for all $i \in\left\{1, \ldots, N_{\mu}\right\} \cap\left\{1, \ldots, N_{\kappa}\right\}$. The symmetry of the firms implies that all strategies are the same, so substituting $q_{i, t}=\omega y_{t}$ into (17) and rearranging terms, the condition that gives parameter $\omega$ is,

$$
\frac{\left(N_{\mu} \omega\right)^{-\frac{1}{\eta}}\left(1-\frac{1}{\eta N_{\mu}}\right)-\rho \nu \omega^{\rho-1}}{\left(N_{\mu} \omega\right)^{-\frac{1}{\eta}}-\nu \omega^{\rho-1}}=\frac{\alpha \delta \theta\left(1-\frac{1}{\eta}\right) \omega}{\left(1-\theta N_{\kappa} \omega\right)^{\frac{1}{\eta}}-\alpha \delta\left(1-\theta N_{\kappa} \omega\right)} .
$$

The strategies of the firms are admissible if the maximization problem of each firm is welldefined. In our setup, the key to admissibility is that $\theta N_{\kappa} \omega \in[0,1)$. Using (13), condition (18) becomes,

$$
g(\chi) \equiv \frac{\left(\theta N_{\kappa}\right)^{\beta} N_{\mu}^{-\frac{1}{\eta}}\left(1-\frac{1}{\eta N_{\mu}}\right) \chi^{-\beta}-\rho \nu}{\left(\theta N_{\kappa}\right)^{\beta} N_{\mu}^{-\frac{1}{\eta}} \chi^{-\beta}-\nu}=\frac{\frac{\alpha \delta}{N_{\kappa}}\left(1-\frac{1}{\eta}\right) \chi}{(1-\chi)^{\frac{1}{\eta}}-\alpha \delta(1-\chi)} \equiv h(\chi),
$$

with $\chi \equiv \theta N_{\kappa} \omega$. The properties of $g(\chi)$ for $\chi \in[0,1]$ are,

$$
g(0)=1-\frac{1}{\eta N_{\mu}}, \quad \text { and } \quad g^{\prime}(\chi)<0,
$$

where $g^{\prime}(\chi)<0$ is implied by the parameter restriction, (14). ${ }^{12}$ The properties of $h(\chi)$ when $\chi \in[0,1]$ are,

$$
h(0)=0, \quad h(1)=\infty, \quad \text { and } \quad h^{\prime}(\chi)>0,
$$

where $h^{\prime}(\chi)>0$, for all $\chi \in[0,1]$ if $\frac{\alpha \delta}{N_{\kappa}}<1$. Whereas, if $\frac{\alpha \delta}{N_{\kappa}}=1, h^{\prime}(1)=0$ and $h^{\prime}(\chi)>0$, for all $\chi \in(0,1] .^{13}$

12For an exhaustive discussion of this point see footnote 15 in Koulovatianos and Mirman [7]. 13Specifically,

$$
h^{\prime}(\chi)=\left(1-\frac{1}{\eta}\right) \frac{\alpha \delta}{N_{\kappa}} \frac{\frac{1-\left(1-\frac{1}{\eta}\right) \chi}{(1-\chi)^{1-\frac{1}{\eta}}}-\alpha \delta}{\left[(1-\chi)^{\frac{1}{\eta}}-\alpha \delta(1-\chi)\right]^{2}} .
$$

Noticing that $1-\left(1-\frac{1}{\eta}\right) \chi \geq(1-\chi)^{1-\frac{1}{\eta}}$, for all $\chi \in[0,1]$ with equality if and only if $\chi=0$, the fact that $\frac{\alpha \delta}{N_{\kappa}} \leq 1$ implies that $h^{\prime}(\chi)>0$, for all $\chi \in(0,1]$. 
Figure 1 summarizes graphically the properties given by (20) and (21), and depicts why the equilibrium strategies, denoted by $\omega^{*}$, in all three market structures, are both admissible (specifically, $\theta N_{\kappa} \omega^{*} \in(0,1)$ ), and unique for the region of non-negative marginal profits, and thus, for the region where each period's profits are strictly positive.

\subsection{The impact of the dynamic externality}

In order to assess the impact of the dynamic externality on firm strategies, and, in particular, whether the 'tragedy of the commons' dominates, we compare the benchmark monopoly case with the case of two monopolies utilizing capital from the same provider. This comparison is given by the following proposition.

Proposition 1 The aggregate exploitation rate of firms in market structure " $m$ " is always higher than the exploitation rate of the benchmark monopoly, " $M$," namely, $\chi_{m}^{*}>\chi_{M}^{*}$

\section{Proof}

Using the fact that $N_{\mu}=1$ in both cases, we can express the right-hand side of (19) as a function of $N_{\kappa}$ as,

$$
G\left(\chi, N_{\kappa}\right) \equiv N_{\kappa} \frac{\left(\theta N_{\kappa}\right)^{\beta}\left(1-\frac{1}{\eta}\right) \chi^{-\beta}-\rho \nu}{\left(\theta N_{\kappa}\right)^{\beta} \chi^{-\beta}-\nu}=\frac{\alpha \delta\left(1-\frac{1}{\eta}\right) \chi}{(1-\chi)^{\frac{1}{\eta}}-\alpha \delta(1-\chi)} \equiv H(\chi)
$$

Since,

$$
G_{2}\left(\chi, N_{\kappa}\right)=\frac{\left(\theta N_{\kappa}\right)^{\beta}\left(1-\frac{1}{\eta}\right) \chi^{-\beta}-\rho \nu}{\left(\theta N_{\kappa}\right)^{\beta} \chi^{-\beta}-\nu}+\frac{\beta \nu \theta^{\beta} N_{\kappa}^{\beta}\left[\rho-\left(1-\frac{1}{\eta}\right)\right]}{\left[\left(\theta N_{\kappa}\right)^{\beta} \chi^{-\beta}-\nu\right]^{2}},
$$

parameter restriction (14) implies that $G_{2}\left(\chi, N_{\kappa}\right)>0$. The equilibrium strategies in the two cases are captured by Figure 2, which proves the proposition.

The implication of Proposition 1 is, as in Levhari and Mirman [8], that the dynamic externality leads to the dominance of the 'tragedy of the commons,' irrespective of the 
parameters affecting the demand function, the cost function, growth possibilities given by $f(k)$, and the endogenous capital depreciation technology.

\subsection{The impact of the market externality in addition to the dy- namic externality}

The starting point for studying the impact of the market externality in addition to the dynamic externality, is the comparison of the market structure of the benchmark monopoly with the market structure of a duopoly with both firms, again, utilizing capital from the same provider.

\subsubsection{Comparison of the benchmark monopoly with a duopoly utilizing capital from the same provider}

We express condition (19) somewhat differently, re-arranging the position of parameter $\rho$ and setting the right-hand side as,

$$
X(\chi)=\frac{\frac{\alpha \delta}{\rho}\left(1-\frac{1}{\eta}\right) \chi}{(1-\chi)^{\frac{1}{\eta}}-\alpha \delta(1-\chi)},
$$

which is common for both cases. The two left-hand sides for the respective market structures are,

$$
\Gamma_{M}(\chi)=\frac{\frac{\theta^{\beta}\left(1-\frac{1}{\eta}\right)}{\rho} \chi^{-\beta}-\nu}{\theta^{\beta} \chi^{-\beta}-\nu}, \quad \text { and } \quad \Gamma_{d}(\chi)=2 \frac{\frac{2^{\rho-1} \theta^{\beta}\left(1-\frac{1}{2 \eta}\right)}{\rho} \chi^{-\beta}-\nu}{2^{\rho-1} \theta^{\beta} \chi^{-\beta}-\nu},
$$

where the parameter constraint (13) has been used. Since the equilibrium conditions in the two market structures, " $M$ " and " $d$, , are $\Gamma_{M}(\chi)=X(\chi)$ and $\Gamma_{d}(\chi)=X(\chi)$, the key is to compare the function $\Gamma_{M}(\chi)$ with $\Gamma_{d}(\chi)$.

To simplify notation, let $\chi^{-\beta} \equiv z, a_{M} \equiv \theta^{\beta}\left(1-\frac{1}{\eta}\right) / \rho, b_{M} \equiv \theta^{\beta}, c \equiv 2^{\rho-1} \theta^{\beta}\left(1-\frac{1}{2 \eta}\right) / \rho$, and $d \equiv 2^{\rho-1} \theta^{\beta}$. Thus, the two definitions in (24) imply that,

$$
\Gamma_{M}(\chi)<\Gamma_{d}(\chi) \Leftrightarrow \frac{a_{M} z-\nu}{b_{M} z-\nu}<2 \frac{c z-\nu}{d z-\nu} .
$$


We consider only strategies that lead to positive profits in both setups. From condition (17) the value function is positive if the marginal profit in each period is positive, namely, if $z>\max \left\{\nu / a_{M}, \nu / c\right\}$.

Proposition 2 The aggregate exploitation rate of firms in market structure " $d$ " is always higher than the exploitation rate of the benchmark monopoly, " $M$," (namely, $\left.\chi_{d}^{*}>\chi_{M}^{*}\right)$.

\section{Proof}

We prove that (25) always holds when profits are positive. For all $z>\max \left\{\nu / a_{M}, \nu / c\right\}$, both $\Gamma_{M}(\chi)$ and $\Gamma_{d}(\chi)$ are strictly positive, so it suffices to show that the stronger condition,

$$
\frac{a_{M} z-\nu}{b_{M} z-\nu}<\frac{c z-\nu}{d z-\nu}
$$

always holds, i.e.,

$$
\frac{a_{M} z-\nu}{b_{M} z-\nu}<\frac{c z-\nu}{d z-\nu} \Leftrightarrow z>\nu \frac{b_{M}+c-a_{M}-d}{c b_{M}-d a_{M}} .
$$

For any values of $\rho$ consistent with $(14), c>a_{M}$, which means that according to the requirement that profits be positive in equilibrium, it must be that $z>\max \left\{\nu / a_{M}, \nu / c\right\}=\nu / a_{M}$. It is easy to show that,

$$
\frac{\nu}{a_{M}}>\nu \frac{b_{M}+c-a_{M}-d}{c b_{M}-d a_{M}} \Leftrightarrow\left(c-a_{M}\right)\left(b_{M}-a_{M}\right)>0
$$

which holds in equilibrium, since, under (14), $b_{M}>a_{M}$, and $c>a_{M}$. Combining the requirement that $z>\nu / a_{M}$ with (28) and (27), proves that (26) holds. This result implies (25) and Figure 3 completes the proof. $\square$

So, for all parameters of the model, the dynamic externality and the market externality, together, lead to overexploitation of capital compared to the benchmark monopoly case. 


\subsubsection{Comparison between strategies of two monopolists utilizing capital from the same provider with the duopoly}

To complete the comparison among all market structures, in this section, we compare the market structure of two monopolists utilizing capital from the same provider, with the market structure of a duopoly with both firms utilizing capital from the same provider.

Using condition (19), rearranging terms, and noting that $N_{\kappa}=2$, in both cases, the right-hand side of the new version of (19) is,

$$
\Xi(\chi)=\frac{\frac{\alpha \delta}{2 \rho}\left(1-\frac{1}{\eta}\right) \chi}{(1-\chi)^{\frac{1}{\eta}}-\alpha \delta(1-\chi)},
$$

whereas the left-hand sides of the resulting equilirium conditions are,

$$
\Lambda_{m}(\chi)=\frac{\frac{(2 \theta)^{\beta}\left(1-\frac{1}{\eta}\right)}{\rho} \chi^{-\beta}-\nu}{(2 \theta)^{\beta} \chi^{-\beta}-\nu}, \quad \text { and } \quad \Lambda_{d}(\chi)=\frac{\frac{2^{-\frac{1}{\eta}}(2 \theta)^{\beta}\left(1-\frac{1}{2 \eta}\right)}{\rho} \chi^{-\beta}-\nu}{2^{-\frac{1}{\eta}}(2 \theta)^{\beta} \chi^{-\beta}-\nu} .
$$

The role of the demand elasticity In a static framework with isoelastic demand functions and a general increasing cost function that implies a unique optimum, the comparison of the aggregate supply of two monopolists with the aggregate supply of the duopolists rests upon the level of demand elasticity. With the demand elasticity below (above) a critical level,

duopolists supply, on aggregate, more (less) than two monopolists. Consistently, Proposition 3 shows that, in our dynamic model, for all parameter values, there is a threshold demand elasticity level below which duopolists supply more than the two monopolists, each utilizing capital from the same source. Yet, unlike the static framework, the comparison may not be reversed when the demand elasticity is above the threshold level.

\section{Low demand elasticity}

Proposition 3 If,

$$
2^{-\frac{1}{\eta}}\left(1-\frac{1}{2 \eta}\right) \geq 1-\frac{1}{\eta} \Leftrightarrow \eta \leq 2.73
$$


the aggregate exploitation rate of firms in market structure " $d$ " is always higher than the aggregate exploitation rate of the benchmark monopoly, " $m$," (namely, $\left.\chi_{d}^{*}>\chi_{m}^{*}\right)$.

\section{Proof}

The two definitions in (30) imply that,

$$
\Lambda_{m}(\chi)<\Lambda_{d}(\chi) \Leftrightarrow \frac{a_{m} z-\nu}{b_{m} z-\nu}<\frac{c z-\nu}{d z-\nu} \Leftrightarrow \frac{d z-\nu}{b_{m} z-\nu}<\frac{c z-\nu}{a_{m} z-\nu},
$$

where $a_{m} \equiv(2 \theta)^{\beta}\left(1-\frac{1}{\eta}\right) / \rho$ and $b_{m} \equiv(2 \theta)^{\beta}$, with the constants $c$ and $d$ defined as above, and with $z$ restricted to values implying positive profits, namely, $z>\max \left\{\nu / a_{m}, \nu / c\right\}$. Using (13), $d=2^{-\frac{1}{\eta}}(2 \theta)^{\beta}<b_{m}$, which implies that,

$$
\frac{d z-\nu}{b_{m} z-\nu}<1
$$

Using (13) again,

$$
c \geq a_{m} \Leftrightarrow 2^{-\frac{1}{\eta}}\left(1-\frac{1}{2 \eta}\right) \geq 1-\frac{1}{\eta} \Leftrightarrow \eta \leq 2.73
$$

yielding,

$$
1 \leq \frac{c z-\nu}{a_{m} z-\nu}
$$

for all $z>\max \left\{\nu / a_{m}, \nu / c\right\}$. Thus, (32) and (33) imply (31). The resulting equilibrium exploitation rate of firms, under the restriction that $\eta \leq 2.73$, is proved by Figure $4 . \square$

Note that the only factor behind the cutoff demand elasticity level, below which the market externality in addition to the dynamic externality leads to more aggregate exploitation for all other parameter values, is the number of firms in the market, $N_{\mu}$.

Steady States for a low demand elasticity $(\eta \leq 2.73) \quad$ When $\phi>0$, the steady state growth of capital is zero. Based on Propositions 1 and 3, the steady-state levels of capital for the three market structures, when $\eta \leq 2.73$, are given by Figure 5, which shows that $k_{d}^{s s}<k_{m}^{s s}<k_{M}^{s s}$. For the case that $\phi=0$ and $\eta \leq 2.73$, growth of the capital stock for a 
duopoly with both firms utilizing capital from the same provider is lower than in the case of two monopolistic firms utilizing capital from the same provider.

Higher demand elasticity $(\eta>2.73)$ In the case $\eta>2.73$, it is possible for the two monopolists to have higher aggregate supply than the duopolists. However, even in our parametric framework, we cannot characterize this possibility analytically. Thus, we present a numerical example, depicted in Figure 6 . The parameter values are $\eta=5(>2.73), \delta=.96$ (reflecting an interest rate of about $4 \%$ ), $\alpha=.3, \rho=1, \theta=.6, \nu=.9$, while $\beta$ is derived using condition (13), i.e. $\beta=.2$ in this example. Figure 6 shows that for these parameter values, $\Lambda_{m}\left(\chi_{m}^{*}\right)>\Lambda_{d}\left(\chi_{m}^{*}\right)$, so $\chi_{d}^{*}<\chi_{m}^{*}$. Thus, given Propositions 1 and $2, k_{m}^{s s}<k_{d}^{s s}<k_{M}^{s s}$. In order to identify the factors that lead to strategies $\chi_{d}^{*}<\chi_{m}^{*}$, in what follows we restrict the numerical example to the parameter values used above, but modify each parameter, one by one, so as to reverse the result, namely to achieve $\chi_{d}^{*}>\chi_{m}^{*}$. This sensitivity analysis reveals the contribution of each parameter. ${ }^{14}$

The impact of a 'more convex' cost function (higher $\rho$ ) A usual determinant of a natural monopoly is that its production function exhibits increasing returns to scale, or, alternatively, a 'slightly convex' or even a concave cost function. In our numerical example, we retain all parameter values at the same level, but we increase the value of $\rho$, by setting $\rho=7$. As can be seen in Figure 7.a, a 'more convex' cost function discourages the two monopolists from supplying more, leading again to $\chi_{d}^{*}>\chi_{m}^{*}$.

The impact of higher capital-renewal elasticity (higher $\alpha$ ) or of a lower interest rate (higher $\delta$ ) A higher $\alpha$ implies a higher renewal elasticity of capital. Setting $\alpha=.7$,

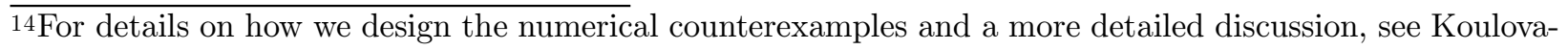
tianos and Mirman [7]. 
with all other parameter values set at the levels of the example of Figure 6, we depict the result in Figure 7.b, where, again $\chi_{d}^{*}>\chi_{m}^{*}$. Note that a higher $\delta$, namely a lower interest rate (the opportunity cost of a firm), leads to the same result as increasing $\alpha .{ }^{15}$

The impact of lower cost (lower $\nu$ ) or of a faster depreciation technology (higher $\theta$ ) In Figure 7.c we have set $\nu=.8$, while for Figure 7.d, we set $\theta=1$. In both of these cases all other parameter values, again, are set at the numerical benchmark of Figure 6 . In both Figures, 7.c and 7.d, the result is that $\chi_{d}^{*}>\chi_{m}^{*}$, unlike the implication of Figure 6 .

To summarize, Proposition 1 states that the dynamic externality leads to more aggregate capital utilization, a 'tragedy of the commons' result. Proposition 2 shows that the impact of the dynamic and the market externality combined leads to more aggregate capital utilization. Proposition 3 states that adding the market externality to a dynamic externality leads to more aggregate capital utilization if the elasticity of demand is sufficiently low with the threshold level of demand elasticity depending only on the number of firms in the market. When the elasticity of demand is above this threshold level, it is possible that adding the market externality to the dynamic externality leads to less aggregate capital utilization, depending on a combined contribution of a relatively low convexity of the cost function, relatively low elasticity of capital renewal, relatively high interest rates, and a relatively weak utilization-dependent depreciation technology.

\section{Isolating the market externality: excludability - duopoly with firms exploiting capital from different providers}

In this section we develop a method for studying the problem of a duopolist without a dynamic externality. We distinguish between two stocks of capital, $k_{A}$ and $k_{B}$, for the firms $A$

15The intrinsic return of keeping a high level of capital is higher if both $\alpha$ is high and if the opportunity cost is low, i.e. if $\delta$ is high. See p. 28-29 in Koulovatianos and Mirman [7]. 
and $B$, respectively. We assume that the initial capital stocks are equal, i.e., $k_{A, 0}=k_{B, 0}>0$. This market structure eliminates the dynamic externality and allows us to study the isolated effects of the market externality.

The capital stocks evolve according to,

$$
k_{A, t+1}=f\left(k_{A, t}\right)-\psi\left(q_{A, t}\right), \quad \text { and } \quad k_{B, t+1}=f\left(k_{B, t}\right)-\psi\left(q_{B, t}\right)
$$

We use the superscript ' $D$ ' for this market structure and we denote the value function of the duopolistic firms as $V^{A, D}$ and $V^{B, D} \cdot{ }^{16}$ The problem of the firm $A$ in a Bellman-equation form is given by,

$$
\begin{aligned}
V^{A, D}\left(k_{A}, k_{B}\right)=\max _{q_{A} \geq 0}\{D & \left(q_{A}+Q^{B, D}\left(k_{A}, k_{B}\right)\right) q_{A}-C\left(k_{A}, q_{A}\right)+ \\
& \left.\quad+\delta V^{A, D}\left(f\left(k_{A}\right)-\psi\left(q_{A}\right), f\left(k_{B}\right)-\psi\left(Q^{B, D}\left(k_{A}, k_{B}\right)\right)\right)\right\},
\end{aligned}
$$

where $Q^{B, D}\left(k_{A}, k_{B}\right)$ is the supply strategy of firm $B$. The problem of firm $B$ is given by switching $A$ and $B$ in the Bellman equation (35). The necessary condition implied by (35) is,

$$
\begin{aligned}
& \quad \frac{D\left(q_{A}+Q^{B, D}\left(k_{A}, k_{B}\right)\right)+D_{1}\left(q_{A}+Q^{B, D}\left(k_{A}, k_{B}\right)\right) q_{A}-C_{2}\left(k_{A}, q_{A}\right)}{\psi^{\prime}\left(q_{A}\right)}= \\
& =\delta\left\{-C_{1}\left(\widehat{k}_{A}, \widehat{q}_{A}\right)+\left[\frac{D\left(\widehat{q}_{A}+Q^{B, D}\left(\widehat{k}_{A}, \widehat{k}_{B}\right)\right)}{\psi^{\prime}\left(\widehat{q}_{A}\right)}+\right.\right. \\
& \left.+\frac{D^{\prime}\left(\widehat{q}_{A}+Q^{B, D}\left(\widehat{k}_{A}, \widehat{k}_{B}\right)\right) \widehat{q}_{A}-C_{2}\left(\widehat{k}_{A}, \widehat{q}_{A}\right)}{\psi^{\prime}\left(\widehat{q}_{A}\right)}\right] f^{\prime}\left(\widehat{k}_{A}\right)+\left[D^{\prime}\left(\widehat{q}_{A}+Q^{B, D}\left(\widehat{k}_{A}, \widehat{k}_{B}\right)\right) \widehat{q}_{A}-\right. \\
& \left.\left.-\delta V_{2}^{A, D}\left(\widehat{\widehat{k}}_{A}, \widehat{\widehat{k}}_{B}\right) \psi^{\prime}\left(Q^{B, D}\left(\widehat{k}_{A}, \widehat{k}_{B}\right)\right)\right] Q_{1}^{B, D}\left(\widehat{k}_{A}, \widehat{k}_{B}\right)\right\},
\end{aligned}
$$

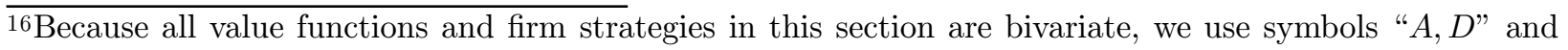
" $B, D$ " as superscripts, in order to allow for partial derivatives to be denoted as subscripts. Despite this slight notational discrepancy with the previous sections, this simplifies the exposition. 
where $\widehat{\widehat{k}}$ is the capital stock two periods ahead. The necessary optimal condition of firm $B$ is given by the same equation as (36), except that $A$ and $B$ are switched.

In this section we show that for the special case of, $\phi=0$, i.e.,

$$
f\left(k_{A}\right)=\alpha^{\frac{\eta}{\eta-1}} k_{A}=Z k_{A} \quad \text { and } \quad f\left(k_{B}\right)=\alpha^{\frac{\eta}{\eta-1}} k_{B}=Z k_{B}
$$

our example can lead to linear supply strategies with respect to $\left(k_{A}, k_{B}\right)$ of the form,

$$
Q^{A, D}\left(k_{A}, k_{B}\right)=\omega_{1} k_{A}+\omega_{2} k_{B}, \quad \text { and } \quad Q^{B, D}\left(k_{A}, k_{B}\right)=\omega_{1} k_{B}+\omega_{2} k_{A} .
$$

Assume that (37) holds, then (34) yields,

$$
\hat{k}_{A}=Z k_{A}-\theta\left(\omega_{1} k_{A}+\omega_{2} k_{B}\right), \quad \text { and } \quad \hat{k}_{B}=Z k_{B}-\theta\left(\omega_{1} k_{B}+\omega_{2} k_{A}\right) .
$$

Using (37) and (38), we construct the value function of firm $A$,

$$
V^{A, D}\left(k_{A}, k_{B}\right)=\frac{\left(\omega_{1}+\omega_{2}\right)^{-\frac{1}{\eta}}\left(k_{A}+k_{B}\right)^{-\frac{1}{\eta}}\left(\omega_{1} k_{A}+\omega_{2} k_{B}\right)-\nu\left(Z k_{A}\right)^{-\beta}\left(\omega_{1} k_{A}+\omega_{2} k_{B}\right)^{\rho}}{1-\beta\left[Z-\theta\left(\omega_{1}+\omega_{2}\right)\right]^{1-\frac{1}{\eta}}} .
$$

The Bellman equation of firm $A$ is,

$$
\begin{aligned}
V^{A, D}\left(k_{A}, k_{B}\right)= & \max _{q_{A} \geq 0}\left\{\left(q_{A}+Q^{B, D}\left(k_{A}, k_{B}\right)\right)^{-\frac{1}{\eta}} q_{A}-\nu k_{A}^{-\beta} q_{A}^{\rho}+\right. \\
+ & \delta \frac{\left(\omega_{1}+\omega_{2}\right)^{-\frac{1}{\eta}}\left(Z k_{A}-\theta q_{A}+Z k_{B}-\theta Q^{B, D}\left(k_{A}, k_{B}\right)\right)^{-\frac{1}{\eta}}}{1-\beta\left[Z-\theta\left(\omega_{1}+\omega_{2}\right)\right]^{1-\frac{1}{\eta}}} \times \\
\times\left[\omega_{1}\left(Z k_{A}-\theta q_{A}\right)+\omega_{2}\left(Z k_{B}-\theta Q^{B, D}\left(k_{A}, k_{B}\right)\right)\right]- & \\
& \left.-\delta \frac{-\nu\left[Z\left(Z k_{A}-\theta q_{A}\right)\right]^{-\beta}\left[\omega_{1}\left(Z k_{A}-\theta q_{A}\right)+\omega_{2}\left(Z k_{B}-\theta Q^{B, D}\left(k_{A}, k_{B}\right)\right)\right]^{\rho}}{1-\beta\left[Z-\theta\left(\omega_{1}+\omega_{2}\right)\right]^{1-\frac{1}{\eta}}}\right\} .
\end{aligned}
$$

Taking the first-order condition first, and, afterwards, imposing symmetry, namely, $\hat{k}_{A}=$ $\hat{k}_{B}=\left[Z-\theta\left(\omega_{1}+\omega_{2}\right)\right] k$ and $q_{A}=q_{B}=\left(\omega_{1}+\omega_{2}\right) k$, under the parameter constraint (13), we arrive at the following equation involving $\omega_{1}$ and $\omega_{2}$,

$2^{-\frac{1}{\eta}}\left(1-\frac{1}{2 \eta}\right)\left(\omega_{1}+\omega_{2}\right)^{-\frac{1}{\eta}}-\rho \nu Z^{-\beta}\left(\omega_{1}+\omega_{2}\right)^{\rho-1}=$ 


$$
=\frac{\delta \theta\left\{2^{-\frac{1}{\eta}}\left(\omega_{1}-\frac{\omega_{1}+\omega_{2}}{2 \eta}\right)+\nu Z^{-\beta}\left[\rho\left(\omega_{1}+\omega_{2}\right)^{\rho-1}-\beta\left(\omega_{1}+\omega_{2}\right)^{\rho}\right]\right\}}{\left[Z-\theta\left(\omega_{1}+\omega_{2}\right)\right]^{\frac{1}{\eta}}-\beta\left[Z-\theta\left(\omega_{1}+\omega_{2}\right)\right]} .
$$

Turning now to the necessary condition given by (36), using the value function, (39), the strategies (37), equations (38), and, imposing the parameter constraint (13) and symmetry, namely, $\hat{k}_{A}=\hat{k}_{B}=\left[Z-\theta\left(\omega_{1}+\omega_{2}\right)\right] k$ and $q_{A}=q_{B}=\left(\omega_{1}+\omega_{2}\right) k$, we arrive at the second equation involving $\omega_{1}$ and $\omega_{2}$,

$$
\begin{aligned}
& 2^{-\frac{1}{\eta}}\left(1-\frac{1}{2 \eta}\right)\left(\omega_{1}+\omega_{2}\right)^{-\frac{1}{\eta}}-\rho \nu Z^{-\beta}\left(\omega_{1}+\omega_{2}\right)^{\rho-1}=\delta\left[Z-\theta\left(\omega_{1}+\omega_{2}\right)\right]^{-\frac{1}{\eta}}\left\{\beta \theta \nu\left(\omega_{1}+\omega_{2}\right)^{\rho}+\right. \\
& +2^{-\frac{1}{\eta}}\left(1-\frac{1}{2 \eta}\right)\left(\omega_{1}+\omega_{2}\right)^{-\frac{1}{\eta}}-\rho \nu Z^{-\beta}\left(\omega_{1}+\omega_{2}\right)^{\rho-1}-\frac{\theta\left(\omega_{1}+\omega_{2}\right)^{-\frac{1}{\eta}}}{2 \eta}- \\
& \left.-\frac{\delta \theta^{2} \omega_{2}\left[2^{-\frac{1}{\eta}}\left(\omega_{1}-\frac{\omega_{1}+\omega_{2}}{2 \eta}\right)-\rho \nu \omega_{2} Z^{-\beta}\left(\omega_{1}+\omega_{2}\right)^{\rho-1}\right]}{\left[Z-\theta\left(\omega_{1}+\omega_{2}\right)\right]^{\frac{1}{\eta}}-\beta\left[Z-\theta\left(\omega_{1}+\omega_{2}\right)\right]}\right\} .
\end{aligned}
$$

Thus, equations (40) and (41) reconfirm that the strategies, $Q^{A, D}\left(k_{A}, k_{B}\right)$ and $Q^{B, D}\left(k_{A}, k_{B}\right)$ are, indeed, linear.

The calculation method we suggest combines the separate information obtained from, (a) the necessary condition with asymmetric stocks, (36), and, (b) from the necessary condition resulting from the Bellman equation, (39), where the implied dynamics of the symmetric strategies have already been imposed on the value function. Yet, in equilibrium, the necessary condition (36), with ex-ante asymmetric stocks (but ex-post symmetry, when calculating $\omega_{1}$ and $\omega_{2}$ ), and the Bellman equation (that has ex-ante the symmetry imposed on the dynamic path leading to the lifetime profits of the firm), give the same information. So, there are two different but equivalent equations, (40) and (41), a $2 \times 2$ system with $\omega_{1}$ and $\omega_{2}$ being the unknowns. Thus, the method we suggest in this section tackles the difficult problem of calculating the equilibrium strategies in an industry with such a market structure. 


\section{REFERENCES}

[1] R. Amir, A lattice theoretic approach to a class of dynamic games, Comp. Math. Appl. 17 (1989) 1345-1349.

[2] J. Benhabib, R. Radner, The joint exploitation of a productive asset: a game-theoretic approach, Econ. Theory 2 (1992) 155-190.

[3] P. K. Dutta, R. K. Sundaram, Markovian Equilibrium in a Class of Stochastic Games: Existence Theorems for Discounted and Undiscounted Models, Econ. Theory 2 (1992) 197-214.

[4] P. K. Dutta, R. K. Sundaram, How Different Can Strategic Models Be? J. Econ. Theory 60 (1993) 42-61.

[5] J. Greenwood, Z. Hercowitz, G. Huffman, Investment, Capacity Utilization, and the Real Business Cycle, Amer. Econ. Rev. 78 (1988) 402-417.

[6] C. Koulovatianos, L. J. Mirman, R\&D Investment, Market Structure, and Industry Growth, mimeo, University of Virginia, 2003.

[7] C. Koulovatianos, L. J. Mirman, The Effects of Market Structure on Industry Growth: Rivalrous Non-Excludable Capital, Working Paper 0501, University of Vienna.

[8] D. Levhari, L. J. Mirman, The Great Fish War: an Example using a Dynamic CournotNash Solution, Bell J. Econ. 11 (1980) 322-334.

[9] L. J. Mirman, Dynamic Models of Fishing: A Heuristic Approach, in: Liu and Sutinen, (Eds), Control Theory in Mathematical Economics, Marcel Dekker, Inc., N.Y., 1979, 39-73.

[10] G. Sorger, A dynamic common property resource problem with amenity value and extraction costs, Int. J. Econ. Theory, 1 (2005) 3-19.

[11] R. Sundaram, Perfect equilibrium in a class of symmetric games, J. Econ. Theory 47 (1989) 153-177. 


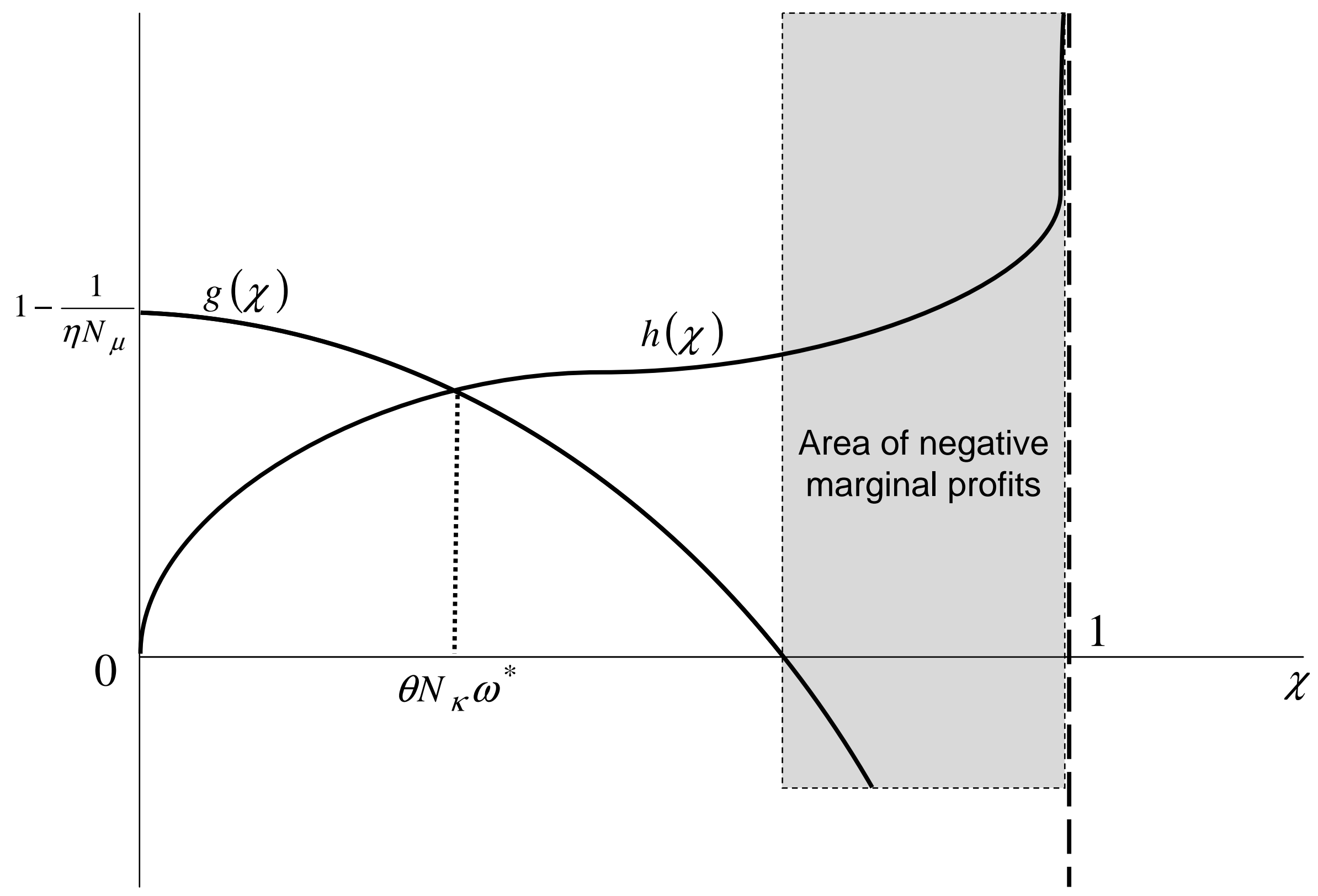

Figure 1 Equilibrium strategies 


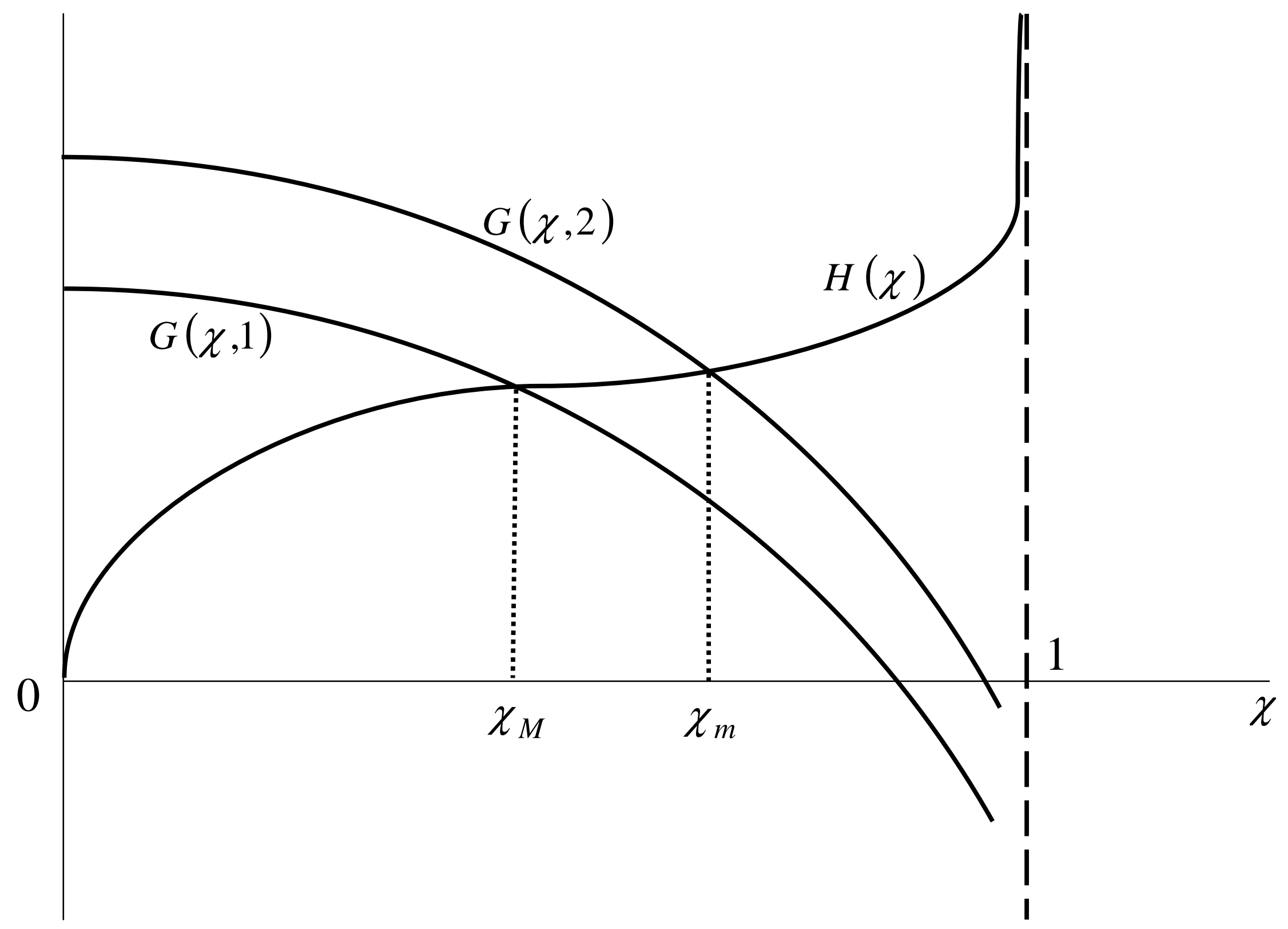

Figure 2 Impact of the dynamic externality on strategies 


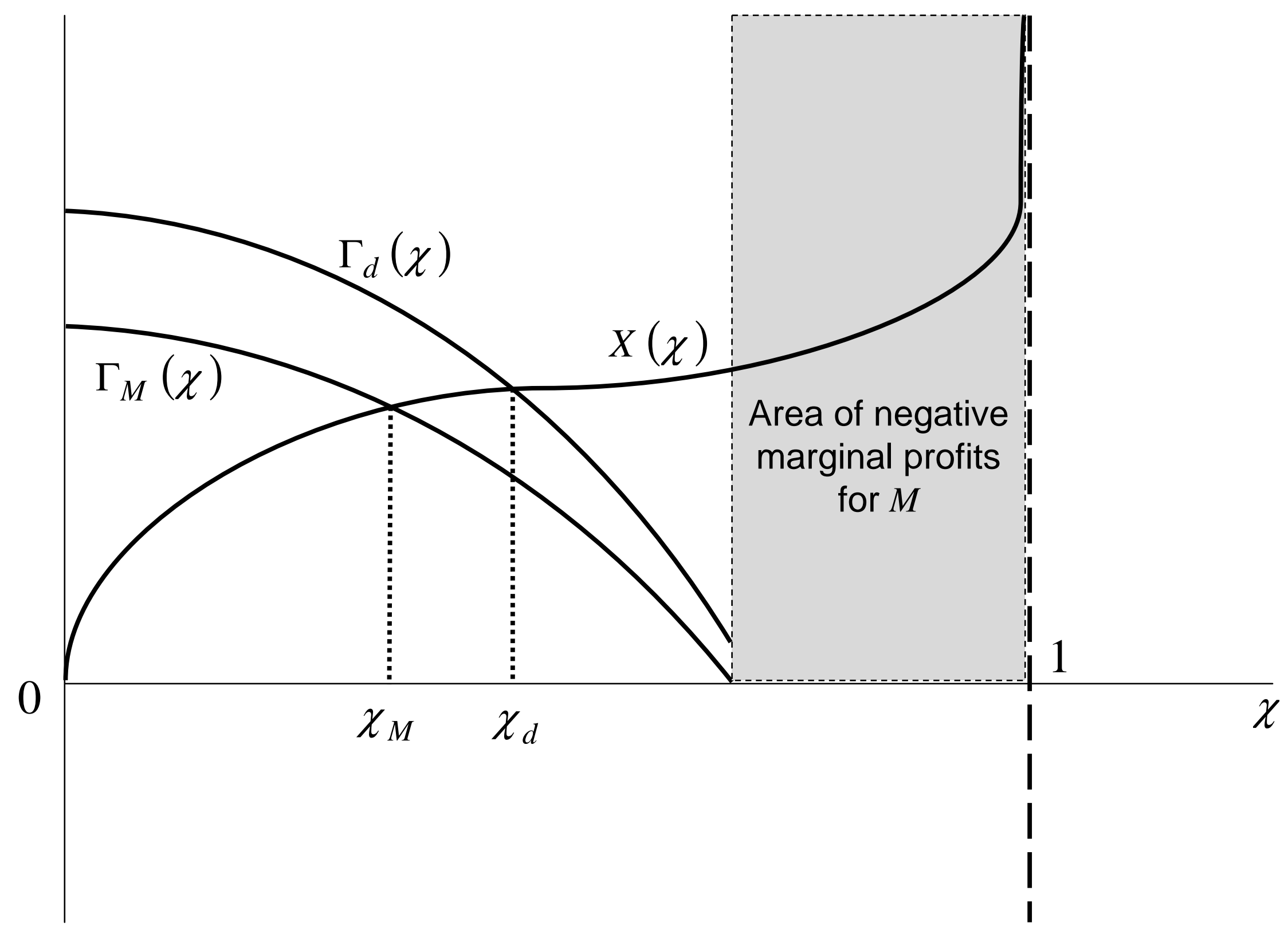

Figure 3 Comparison of $\chi_{M}$ and $\chi_{d}$ 


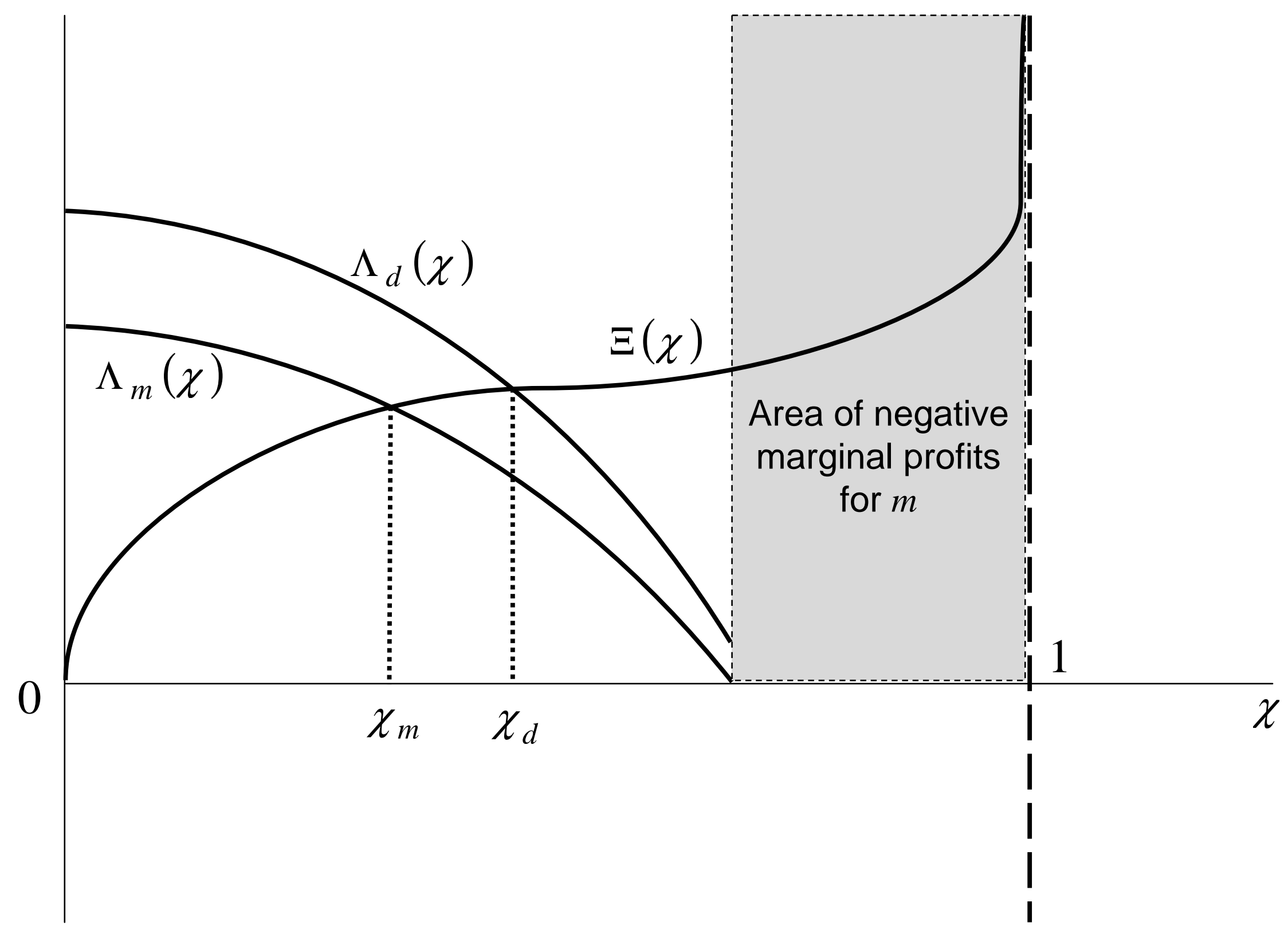

Figure 4 Comparison of $\chi_{m}$ and $\chi_{d}$ when $\eta \leq 2.73$ 


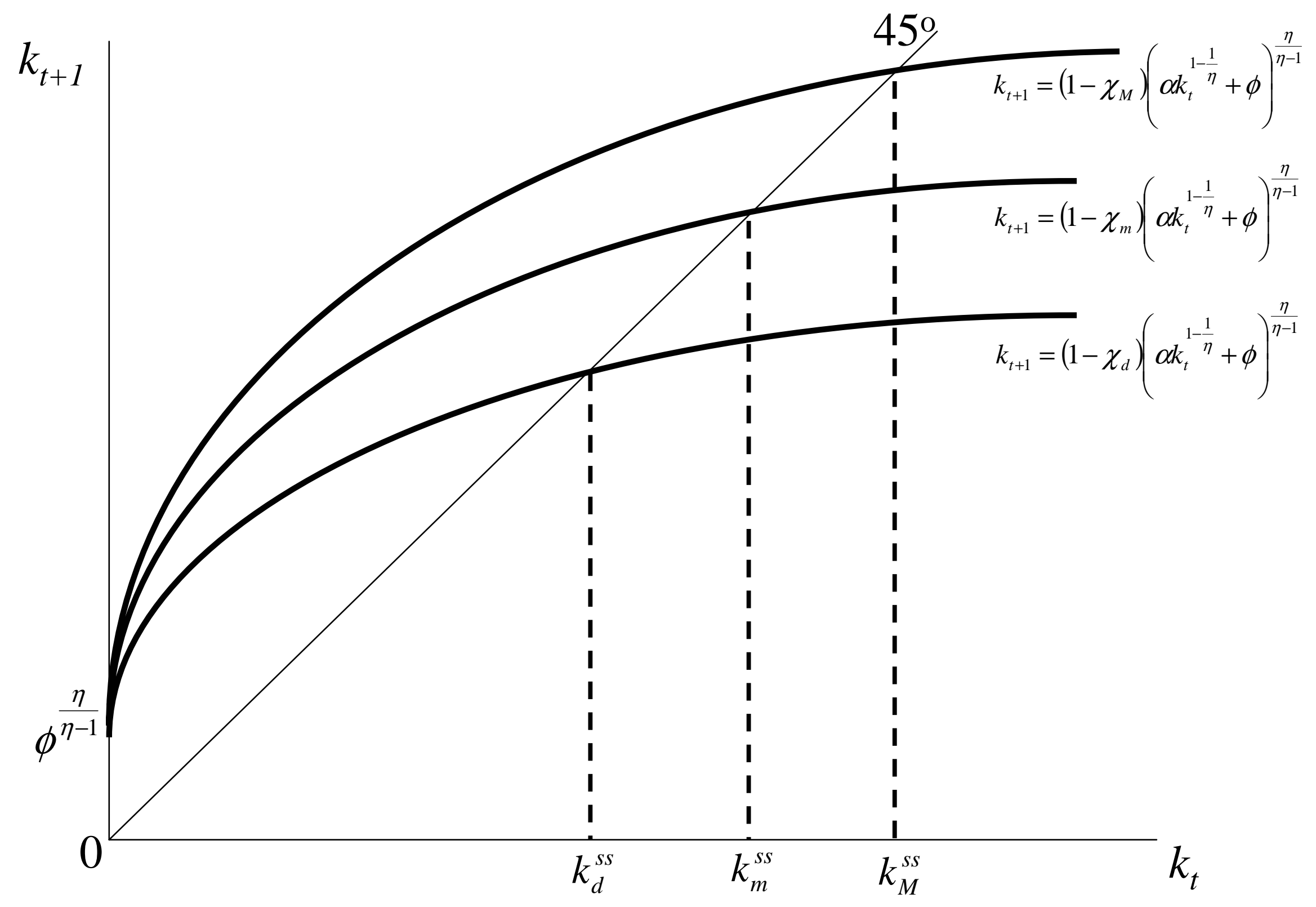

Figure 5 Comparison of steady states for different market structures: $\eta \leq 2.73$ 
Figure 6 - Example of a case where $\chi_{m}>\chi_{d}$

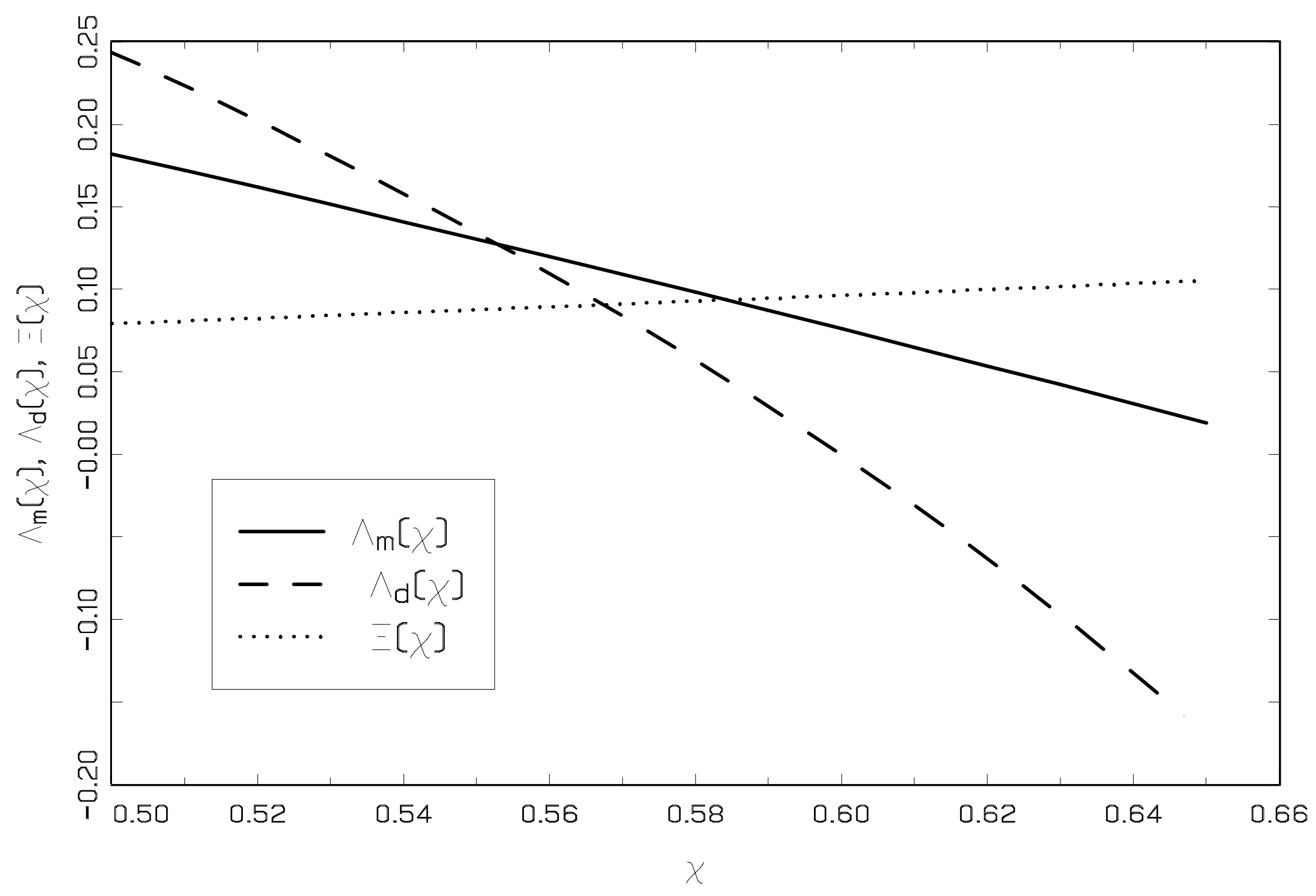


Figure 7.a - Higher $\rho$

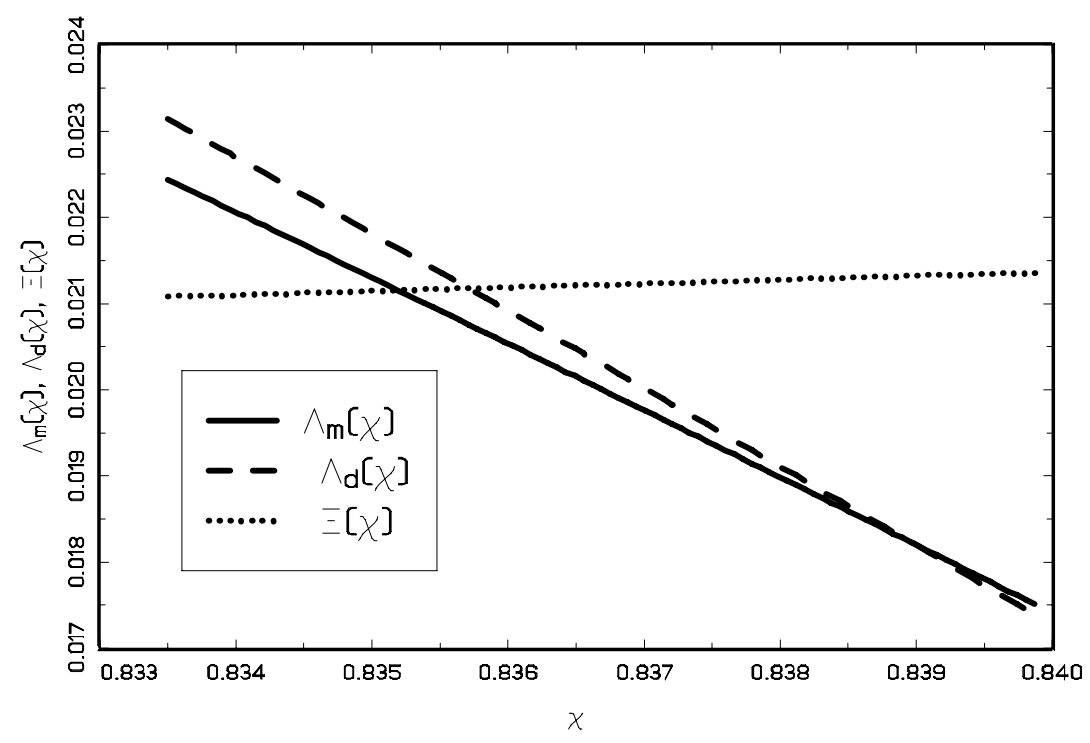

Figure 7.c - Lower 2

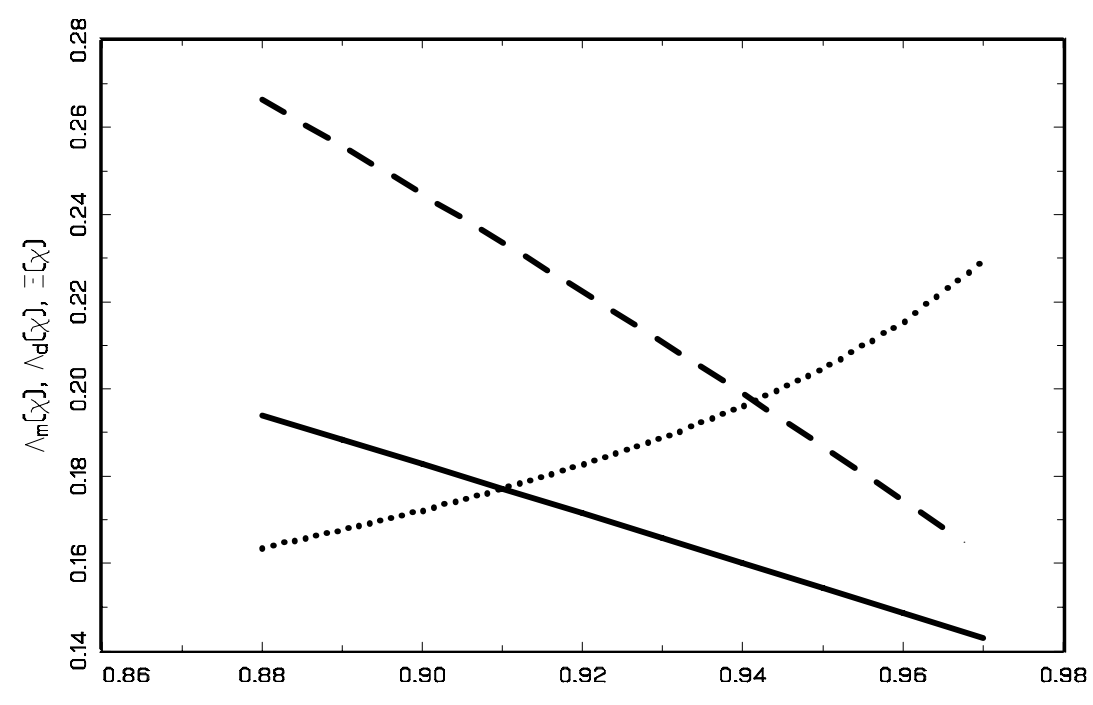

Figure 7.b - Higher $\alpha \subset \delta \supset$

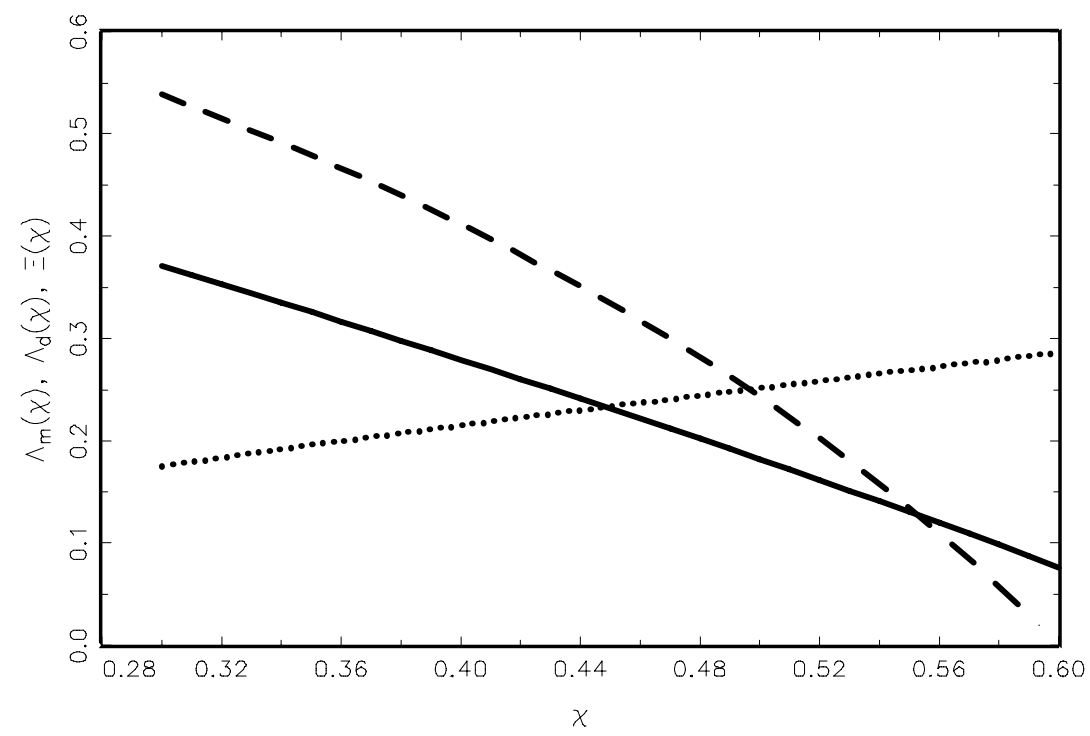

Figure 7.d - Higher $\ominus$

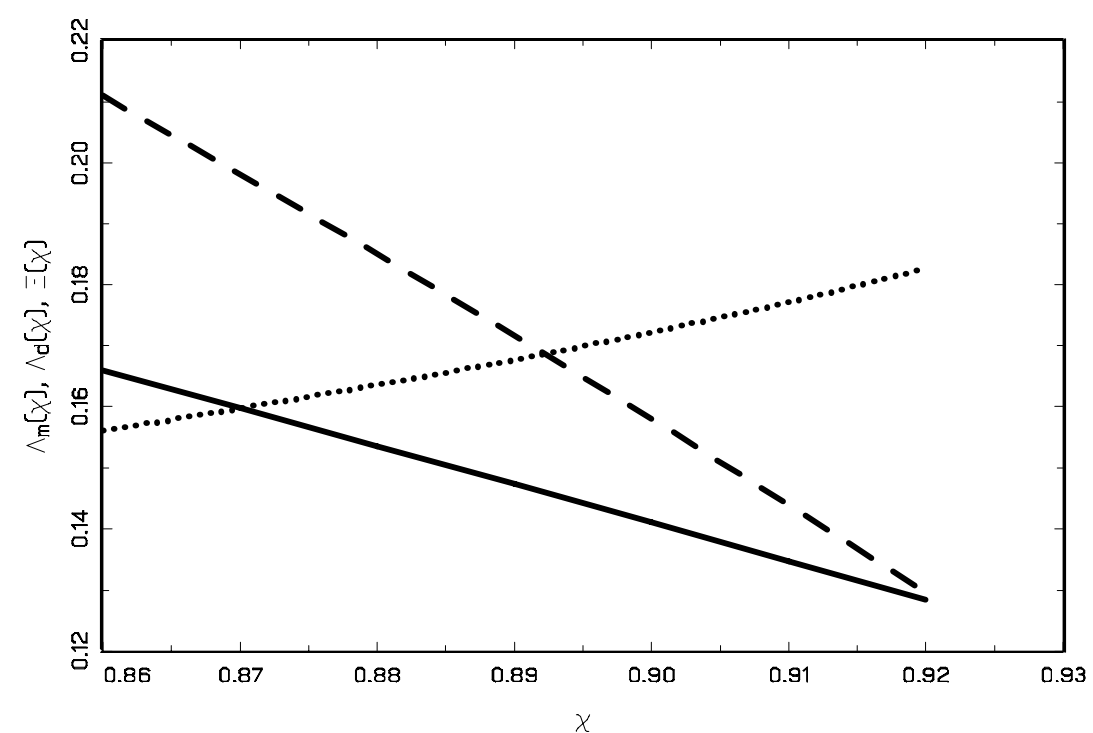

